\title{
ANALYSIS OF TECHNOLOGY READINESS AND TECHNOLOGY ACCEPTANCE OF GEODESY STUDENT IN USING INA GEOPORTAL
}

\author{
Rorim Panday \\ Bhayangkara Jaya University,Management, Jakarta,Indonesia \\ indripan@gmail.com
}

\begin{abstract}
Spatial information system has been widely used for a variety of spatial planning. The planning can be done on a google map. But, on google map, information is still limited. Indonesia has already a system similar to google maps called Ina Geoportal, which covers an area of Indonesia only. In this system anyone can use for a spatial information system and can be shared to other users. Ina Geoportal created web-based and Arc GIS based. One user of Ina geoportal is Geodesy education. Because Ina Geoportal with regard to the application of IT, it is interesting to study how the level of technology readiness and technology acceptance of Geodesy students especially with the use of Ina geoportal. For this study conducted at sample of Geodesy students of Pakuan University as many as 100 students by using a questionnaires developed from questionnaires Parasuraman and Davis. For data processing to test the validity, reliability and Path analysis using SPSS ver.17 and Amos ver 18 software. Results from this study indicate Optimism and Innovativeness factors are high enough; and significant influence on technology acceptance. While the inhibitors factors of insecurity and discomfort are also quite high, but do not affect to the technology acceptance. The effect of technology acceptance on the usage level of Ina geoportal is very low (5.1\%). Based on this, Ina geoportal usage rate is not only influenced by the technology readiness and technology acceptance, but can also be caused by other factors, which are discussed in this paper.
\end{abstract}

Keywords: technology readiness, technology acceptance, Ina geoportal, geographic information systems

\section{INTRODUCTION}

Spatial information system technology is now grown very rapidly, both in terms of hardware, software and applications, especially with the availability of google map. Google map has been widely used by various parties in planning whether business planning, engineering planning, economic planning, social, cultural and even defense and security. Google map only provide information about the location and condition of a place, has not provided complete information about the state of spatial / other spatial shown on the Google map. For national interests, Indonesia has made the system of spatial information created by the Geospatial Information Agency named Ina -Geoportal. This information system similar to google map, but is devoted to the territory of Indonesia. This information system is prepared, to occur one map policy (Karsidi, 2014). With the Ina-Geoportal, then anyone else, ministries, state agencies, privates sector, communities and universities, who will perform spatial planning, or provide spatial information, using the same map. With the same map, the planning or information created can be used or processed together, because it uses a map at the same scale and the same reference system. Ina Geoportal made on the terms Arc GIS-based and Web-based, so the map of Ina Geoportal can be accessed via the Internet, are used, compiled, saved back in sharing to the other user the Ina Geoportal (Badan Informasi Geospasial, 2012). Anyone can use the Ina Geoportal, as it comes with a guide to using Ina Geoportal. One of the users of Ina-Geoportal is Geodesy education, where students can use it for the final task or learning in constructing a geographical information system. Because Ina geoportal IT-based, then it becomes interesting to see the level of usage of the Ina Geopotal.

Based on previous research, the level of IT usage, highly dependent on the technology readiness level (Technology Readiness) and the level of acceptance of technology (Technology acceptance) of the person who uses the IT, as expressed by Parasuraman and Davis. From observations of researchers, Ina Geoportal is still a few people use it and also the world of education, especially Geodesy education that utilizes Ina Geoportal. It can be seen from the features sharing within the Ina Geoportal are still a few. Because Ina Geoportal is very closely related to the disciplines of Geodesy, so in this study will be analyzed how the level of technological readiness and the level of acceptance of the technology from the students of Geodesy in using Ina Geoportal. From the results of this study are expected to be 
useful for Geodesy study program to prepare the infrastructure for the students of Geodesy in using Ina Geoportal, for learning purposes, final project and geographic information systems project execution, improve learning systems so that geodesy students are more interested in using Ina Geoportal..

\section{REVIEW OF LITERATURE}

This study, supported by the theory of technology readiness (TR) which introduced by Parasuraman and technology acceptance model (TAM) which developed by Parasuraman and Davis.Technology readines (TR) is refers to "people's propensity to embrace and use new technologies to accomplish goals in home life and at work" (Parasuraman, 2000, p. 308).

Technology readiness consist of four personality dimensions: optimism, innovativeness, discomfort, and insecurity. According to Parasuraman (2000) these personality dimensions affect people's tendency to embrace and use new technologies. In this respect optimism and innovativeness function as mental enablers, while discomfort and insecurity function as mental inhibitors to accept new technologies. TR is individual belief to technology, which can be positive belief or negative belief, can be exist in a individual. Each individual has vary this beliefs (Parasuraman \& Colby 2001). Parasuraman \& Colby have defined those four dimensions. The four dimensions are fairly independent, each of them making a unique contribution to an individual's technology readiness (Parasuraman \& Colby, 2001).

Another theory is the technology acceptance model (TAM), which introduced by Davis (1989, p. 320); In TAM there are two central determinants: Perceived usefulness, which refers to "the degree to which a person believes that using a particular system would enhance his or her job performance" (Davis, 1989, p. 320); and perceived ease of use, which refers to "the degree to which a person believes that using a particular system would be free of effort" (Davis, 1989, p. 320). TAM was designed specifically to explain computer usage behaviour. It is an adaptation of Fishbein and Azjen's (1975) theory of reasoned action (TRA), which has been successful in predicting and explaining behaviour in general (Malhotra \& Galletta, 1999; Yi \& Hwang, 2003).

Following the theoretical basis of TRA these perceived characteristics are expected to influence intensions to use a system, which in turn influence actual system usage (Davis et al., 1989).

The TAM has received considerable support over the years and over a wide range of systems, and perceived usefulness and perceived ease of use have proven to be reliable and valid cognitive dimensions (Burton-Jones \& Hubona, 2006; King \& He, 2006). TRAM has been used in two research by (Panday, 2015a) in the paper title The Effect of Technology Readiness on Technology Acceptance in Using Services Delivery of Academic Information System and in the paper (Panday, 2015b) title Evaluation of Technology ReadinessAcceptance in Operation of Project Management Services. This integrated model has been used by several researcher from other country which have been mention in the last two paper of the researcher. To see those related research, this study is different from previous studies in term in object and subject of the study.

\section{METHODOLOGY}

The aims this study to reveal the effects of technology readiness on technology acceptance in the implementation of Ina Geoportal and to see their relationship in TRAM (Technology Readiness-Acceptance Model). This study is a quantitative study using a questionnaire that was developed by Parasuraman for TRI and Davis for TAM, and make some adjusment for subject target. The questionnaire was translated into Indonesian, and given to the respondents those are Geodesy students at Pakuan University. The sum of respondents as convenience sample, are 100 students. After tabulated data, validity and reliability of data computed by using Pearson correlation and Cronbach coefficient. To compute the data and TRAM, used SPSS ver.17 and AMOS 18. The figure of path analysis model is as follows:

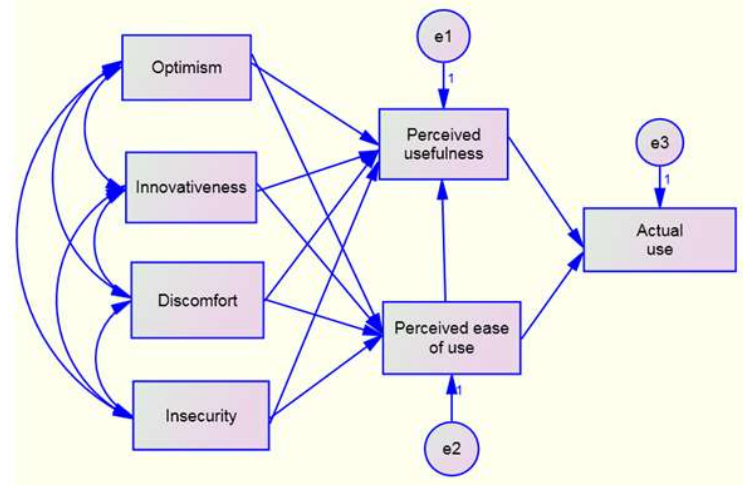

Figure 1. The integrated model TRAM

Of the model made the following hypothesis :

H1. Optimism is positively related to perceived usefulness.

H2. Optimism is positively related to perceived ease of use.

H3. Innovativeness is positively related to perceived usefulness. 
H4. Innovativeness is positively related to perceived ease of use.

H5. Insecurity is negatively related to perceived usefulness.

H6. Insecurity is negatively related to perceived ease of use.

(Parasuraman \& Colby, 2001; Tsikriktsis, 2004).

H7. Discomfort is not significantly related to perceived usefulness.

H8. Discomfort is negatively related to perceived ease of use.

H9. Perceived ease of use is positively related to perceived usefulness. (King \& He, 2006; Lin et al., 2005; McFarland \& Hamilton, 2004; Schepers \& Wetzels, 2007; Venkatesh, 2000; Yang \& Yoo, 2004).
H10. Perceived usefulness is positively related to actual use. H11. Perceived ease of use is positively related to actual use. Davis (1989) (Schepers \& Wetzels, 2007).

\section{RESULT AND DISCUSSION}

Before the path analysis, the first to test the validity and reliability of the data. The Result shown at table-1. Look to Pearson Correlation values for each indicator has been greater than 0.3 and significant at the 0.01 level. Thus it can be said to be valid data. And for the value of reliability for each variable has been greater than 0.6 ; so that it can be said that the data obtained is reliable.

Table 1 . Validity and reliability result

\begin{tabular}{|c|c|c|c|c|c|c|c|c|c|c|c|}
\hline \multicolumn{12}{|c|}{ Validity } \\
\hline & $\begin{array}{c}\text { Pearson } \\
\text { Corr. }\end{array}$ & & $\begin{array}{c}\text { Pearson } \\
\text { Corr. }\end{array}$ & & $\begin{array}{l}\text { Pearson } \\
\text { Corr. }\end{array}$ & & $\begin{array}{c}\text { Pearson } \\
\text { Corr. }\end{array}$ & & $\begin{array}{c}\text { Pearson } \\
\text { Corr. }\end{array}$ & & $\begin{array}{c}\text { Pearson } \\
\text { Corr. }\end{array}$ \\
\hline op1 & $.666^{* \pi}$ & $\ln 1$ & $.608^{\pi x}$ & Dls1 & $.635^{\times x}$ & Ins1 & $.274^{\pi *}$ & Pu1 & $.776^{\pi x}$ & Pe1 & $.884^{\pi *}$ \\
\hline op2 & $.499^{\prime \prime \prime}$ & $\ln 2$ & $.755^{\circ \prime}$ & Dis2 & $.419^{\prime \prime}$ & Ins2 & .620 & Pu2 & $.715^{\prime \prime}$ & $\mathrm{Pe} 2$ & $.807^{\prime \prime \prime}$ \\
\hline op3 & $.800^{* \pi}$ & $\ln 3$ & $.576^{\pi n}$ & Dis3 & $.432^{n \prime}$ & Ins3 & $.427^{\pi n}$ & Pu3 & $.526^{\pi n}$ & $\mathrm{Pe} 3$ & $.340^{n \prime}$ \\
\hline op4 & .662 & $\ln 4$ & .568 & Dis4 & .511 & Ins4 & $.620^{\circ}$ & Pu4 & .434 & Pe4 & $.660^{n}$ \\
\hline op5 & $.857^{\circ \pi}$ & $\ln 5$ & $.562^{* \pi}$ & Dis5 & $.403^{\pi x}$ & Ins5 & $.531^{\pi x}$ & Pu5 & $.526^{\pi m}$ & Pe5 & $.350^{* *}$ \\
\hline op6 & $.807^{\circ \prime \prime}$ & $\ln 6$ & $.646^{\pi x}$ & Dis6 & $.544^{\pi x}$ & Ins6 & $.636^{\pi n}$ & Pu6 & $.774^{\circ}$ & Pe6 & $.884^{\pi x}$ \\
\hline op7 & $.828^{\prime \prime}$ & $\ln 7$ & $.645^{\prime}$ & Dis7 & .448 & Ins7 & $.563^{\prime}$ & & & & \\
\hline op8 & .854 & & & Dis8 & $.635^{m \prime}$ & Ins8 & $.582^{n \prime \prime}$ & & & & \\
\hline op9 & $.840^{\circ}$ & & & Dis9 & .371 & Ins9 & $455^{\star *}$ & & & & \\
\hline Op10 & $.776^{\star *}$ & & & Dis10 & $.577^{\star *}$ & & & & & & \\
\hline \multicolumn{2}{|c|}{ Realibility } & \multicolumn{2}{|c|}{ Realibility } & \multicolumn{2}{|c|}{ Realibility } & \multicolumn{2}{|c|}{ Realibility } & \multicolumn{2}{|c|}{ Realibility } & \multicolumn{2}{|c|}{ Realibility } \\
\hline \multicolumn{2}{|c|}{0,916} & \multicolumn{2}{|c|}{0,736} & \multicolumn{2}{|c|}{0,657} & \multicolumn{2}{|c|}{0,665} & \multicolumn{2}{|c|}{0,702} & \multicolumn{2}{|c|}{0,710} \\
\hline
\end{tabular}

$$
\text { ** Sig pada } 0,01
$$

The average value for each indicator of technology readiness and technology acceptance presented in Table 2 . The average value of each indicator Optimism is greater than 3, or even greater than 4; while the average value Optimism is 3.93 . This means that Geodesy students having faith in technology is high. The average value of each indicator Innovativenss above 3 and 4; Whereas the average score innovativenes was 3.76 , indicating a high value innovativeness. Thus, the driving force for technology readiness elements of Geodesy students is high. The average value of Discomfort is 3.66 and the average value of insecurity is 3.67 ; show a high enough value. So it can be said the inhibitor factor of geodesy students to be ready for technology is high enough. Overall, the technology readiness of Geodesy students is still low. If the average value of optimism summed with the average value Innovativeness, reduced by the sum of the average value of discomfort and insecurity, then the value of technology readiness is 0.36 . This is based on the premise that Optimism and Innovativeness is the driving factor, while discomfort and insecurity is a prohibitive factor. The average value of perceived usefulnes is 3.69 , means that the conviction will technology provides many benefits (perceived usefulness), considered quite high. The average value of the perceived ease of use was 3.88 can also be said to be high, meaning that the geodesy students have to have confidence can easily use the technology Ina geoportal. So it can be said of the student geodesy technology acceptance is high. Ina geoportal usage rate by geodetic student, as average was 3.72 of a scale of 7 in the questionnaire, it can be said usage level is not too high or mediocre. 
Table 2. Average value each indicator and variable

\begin{tabular}{|c|c|c|c|c|c|c|c|c|c|c|c|}
\hline op1 & op2 & op3 & op4 & op5 & op6 & op7 & op8 & op9 & op10 & T_opt & Rata-rata \\
\hline 3,68 & 3,41 & 3,74 & 4,17 & 4,16 & 4 & 4,04 & 4,17 & 4,04 & 3,89 & 39,3 & 3,93 \\
\hline in1 & In2 & in3 & in4 & in5 & in6 & in7 & T_in & & & & \\
\hline 3,54 & 3,6 & 4,08 & 3,43 & 4,09 & 3,51 & 4,04 & 26,29 & & & & 3,76 \\
\hline dis1 & dis2 & dis3 & dis4 & dis5 & dis6 & dis7 & dis8 & dis9 & dis10 & T-Dis & \\
\hline 3,68 & 3,72 & 3,73 & 3,72 & 3,69 & 3,71 & 3,69 & 3,68 & 3,69 & 3,31 & 36,62 & 3,66 \\
\hline Ins1 & Ins2 & Ins3 & Ins4 & Ins5 & Ins6 & Ins7 & Ins8 & Ins9 & T-ins & & \\
\hline 3,76 & 3,71 & 3,71 & 3,69 & 3,57 & 3,7 & 3,45 & 3,73 & 3,72 & 33,04 & & 3,67 \\
\hline Pu1 & Pu2 & Pu3 & Pu4 & Pu5 & Pu6 & T_pu & & & & & \\
\hline 3,41 & 3,74 & 4,08 & 3,43 & 4,08 & 3,4 & 22,14 & & & & & 3,69 \\
\hline pe1 & pe2 & pe3 & pe4 & pe5 & pe6 & T_pe & & & & & \\
\hline 4 & 4,04 & 3,51 & 4,04 & 3,7 & 4 & 23,29 & & & & & 3,88 \\
\hline
\end{tabular}

The result of path analysis shown at figure 2. And table 3

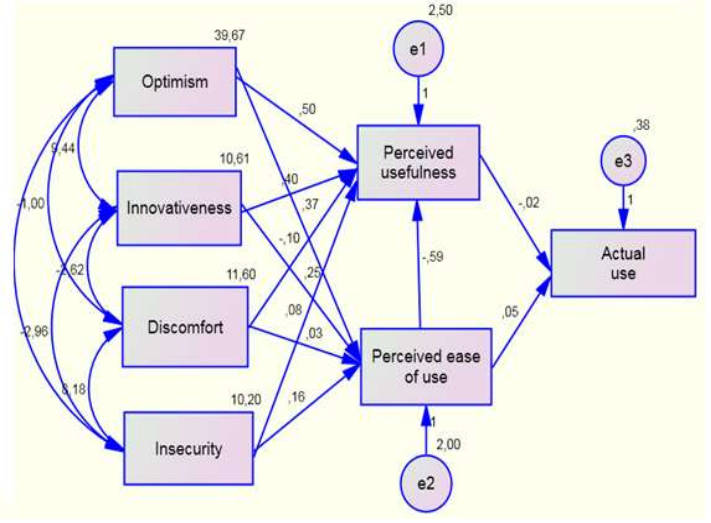

Figure 2. The Result of Path Analisis computation

Tabel 3. Regression Weights

\begin{tabular}{|l|l|l|r|r|r|r|l|}
\hline & & & Estimate & S.E. & C.R. & P & note \\
\hline $\begin{array}{l}\text { Perceived } \\
\text { usefulness }\end{array}$ & $<---$ & Optimism &, 502 &, 050 & 9,948 & $* * *$ & H1 supported \\
\hline Perceived ease of use & $<---$ & Optimism &, 371 &, 026 & 14,540 & $* * *$ & H2 supported \\
\hline Perceived usefulness & $<---$ & Innovativeness &, 401 &, 064 & 6,296 & $* * *$ & H3 supported \\
\hline Perceived ease of use & $<---$ & Innovativeness &, 248 &, 051 & 4,850 & $* * *$ & H4 supported \\
\hline Perceived usefulness & $<---$ & Insecurity &, 079 &, 079 & 1,008 &, 314 & H5 not supported \\
\hline Perceived ease of use & $<---$ & Insecurity &, 162 &, 068 & 2,370 &, 018 & H6 not supported \\
\hline Perceived usefulness & $<---$ & Discomfort &,- 098 &, 071 & $-1,382$ &, 167 & H7 supported \\
\hline Perceived ease of use & $<---$ & Discomfort &, 030 &, 063 &, 480 &, 631 & H8 not supported \\
\hline Perceived usefulness & $<---$ & $\begin{array}{l}\text { Perceived ease of } \\
\text { use }\end{array}$ &,- 588 &, 112 & $-5,241$ & $* * *$ & H9 supported \\
\hline actual_use & $<---$ & Perceived usefulness &,- 018 &, 025 &,- 725 &, 468 & H10 not supported \\
\hline actual_use & $<---$ & $\begin{array}{l}\text { Perceived ease of } \\
\text { use }\end{array}$ &, 052 &, 023 & 2,235 &, 025 & H11 supported \\
\hline
\end{tabular}


Reffered to path computation, at table 3 , there are seven hyphotheses are proven, those are $\mathrm{H} 1, \mathrm{H} 2, \mathrm{H} 3, \mathrm{H} 4, \mathrm{H} 7, \mathrm{H} 9$ dan $\mathrm{H} 11$; and 4 hyphotheses are not proven. For the hypothesis that proved, $\mathrm{H} 1$ to $\mathrm{H} 4$, indicated by probability value less than 0,$05 ; \mathrm{H} 7$ indicated by $\mathrm{p}$ value $>0,05, \mathrm{H} 9$ and $\mathrm{H} 11$ indicated by $\mathrm{p}$ value $<0,05$. For hypothesis is not proven, those are $\mathrm{H} 5, \mathrm{H} 6, \mathrm{H} 8$ and $\mathrm{H} 10$, indicated by $\mathrm{P}$ value $>0,05$ and have a relationship that is contrary to the hypothesis. Geodetic Students have high of the optimism and innovativess, as the driving force for use Ina geoportal technology; also proved, give affects their belief in the usefulness of ina geoportal (perceived usefulness) and the belief for use ina geoportal easily (perceived ease of use). From the descriptive analysis, conviction of geodesy students to the usefulness of ina geoportal (perceived usefulness) and the conviction for easy use (perceived ease to use) is also high, so the technology acceptance of geodesy students is high. Of the two elements of the technology acceptance, confidence to use the technology easily of ina geoportal which gives an effect on the level of usage of ina geoportal technology.At the inhibitor side of technology readiness of geodesy students, although they have a high level of insecurity, but this inhibitor element in using the technology does not give effect to the belief of usefulness (perceived usefulness) ina geoportal and belief in ease of use (perceived ease of use) of Ina geoportal. For the discomfort element, which they are high, no effect on their confidence in the usefulness (Perceived usefulness) ina geoportal and no effect on confidence easy to use (perceived ease of use) of Ina geoportal. From this description, for geodesy students, they have high optimism and innovativeness, effect on belief in the usefulness and confidence at easy to use ina geoportal, which in the end the confidence at easy to use influence on the usage rate of Ina geoportal.

Table 4. Squared Multiple Correlations

\begin{tabular}{|l|r|}
\hline & Estimate \\
\hline Perceived ease of use &, 793 \\
Perceived usefulness &, 719 \\
actual_use &, 051 \\
\hline
\end{tabular}

The contribution of optimism and Innovativeness to the confidence to be easy to use (perceived ease of use) amounted to $79.3 \%$; whereas its contribution to the belief in the usefulness ina geportal is $71.9 \%$. The contribution of technology acceptance of Geodesy student against Ina geoportal usage rate is $5.1 \%$. It is quite interesting, because with optimism, innovativeness, and technology acceptance high, the effect on the level of usage is still very low at 5.1\%. It means that there are other things that affect to the usage rate of the Ina geoportal; namely it the knowledge base that supports to run Ina geoportal inadequate, or has not mastered, such as the ability of geodesy students in the science of geographic information system is not adequate, so to use ina geoportal they are still undecided. Another thing to mention, is their ability to run software in Web -based and GIS -based base is inadequate. What else hardware and software facilities on campus are also not support them to do lab work or experiment with using Ina geoportal. Internet facilities on campus are also not sufficient for them to experiment with Ina geoportal. Thereby to increase the use of Ina geoportal, then things that should be improved are:

1. To improve and increase the syllabus / module associated with the design or manufacture of geographic information systems.

2. To improve the geodetic computer laboratory facilities, such as computer facilities which are adequate for the amount of students there, support by adequate GIS software and Internet networks that support both in terms of capacity and speed.

3. To increase the frequency of use of Ina geoportal by conducting joint research between students and students or between students and faculty and between the faculty associated with the geospatial.

\section{Conclusions}

As conclusion of this researach as follows:

1. Technology readiness of geodesy student is quite high interm of optimism and innovativeness factors. These enabler factors effect to the technology acceptance of geodesy students, whereby the techonology acceptance also quite high.

2. The inhibitor factors of technology readiness which consist of insecurity and discomfort, of geodesy students is also quite high, but these inhibitor factors do not effect to the the technology acceptance of geodesy students.

3. Usage rate of Ina geoportal in very low, although the usage rate influence by high technology acceptance.

4. The low of usage rate is not only depent on technology readiness and technology acceptance, but can be influenced by another factors, beside of the 
individualism factors such as technology readiness and technology acceptance. The another factors that influence to the usage rate of ina geoportal can be: not adequate knowledge of the students, infrastructure in-adequate for practising, lack of conduct more research related to geospatial information.

\section{REFERENCES}

Badan Informasi Geospasial (2012).Petunjuk Teknis Penggunaan Ina Geoportal, ver.01

Burton-Jones, A., \& Hubona, G. S. (2006). The mediation of external variables in the technology acceptance model. Information \& Management, 43, 706-717. doi:10.1016/j.im.2006.03.007

Davis, F. D. (1989). Perceived usefulness, perceived ease of use, and user acceptance of information technology. MIS Quarterly, 13, 319-340. doi:10.2307/249008

Fishbein, M., \& Ajzen, I. (1975). Belief, attitude, intention, and behavior: An introduction to theory and research. Reading, MA: Addison-Wesley.

Karsidi, Asep (2014). New paradigm Geospatial Information Development and one Map Policy In Indonesia, for disaster mitigation and Risk management. Presenting at Beijing, October 2014.

King, W. R., \& He, J. (2006). A meta-analysis of the technology acceptance model. Information \& Management, $\quad 43, \quad 740-755$. doi:10.1016/j.im.2006.05.003

Lin, C.-H., Shih, H.-Y., Sher, P. J., \& Wang Y.-L. (2005). Consumer adoption of e-service: Integrating technology readiness with the technology acceptance model. Proceedings of PICMET '05: Technology Management: A Unifying Discipline for Melting the Boundaries, Portland, Oregon, USA, 483-488. doi:10.1109/PICMET.2005.1509728

Malhotra, Y., \& Galletta, D. F. (1999). Extending the technology acceptance model to account for social influence: Theoretical bases and empirical validation. Proceedings of the $32^{\text {nd }}$ Hawaii International Conference on System Sciences, Maui, Hawaii, USA, 114. doi:10.1109/HICSS.1999.772658

McFarland, D. J., \& Hamilton, D. (2006). Adding contextual specificity to the technology acceptance model. Computers in Human Behavior, 22, 427-447. doi:10.1016/j.chb.2004.09.009.

Panday, Rorim(2015a). The Effect of Technology Readiness on Technology Acceptance in Using Services Delivery of Academic Information System. Presenting and publishing in proceeding, at 12th International Symposiom on Management (Insyma) 2015 by Surabaya University, at Makassar, March 13-15, 2015.

Panday, Rorim (2015b). Evaluation of Technology Readiness-Acceptance in Operation of Project Management Services. Presenting and publishing in proceeding, at 1st Joint Conference Indonesia Malaysia, Bangladesh and Ireand at Ubudiyah Indonesia University, Banda Aceh, Indonesia, 27-28 April 2015.

Parasuraman, A. (2000). Technology readiness index (TRI): A multiple-item scale to measure readiness to embrace new technologies. Journal of Service Research, 2, 307320. doi:10.1177/109467050024001

Parasuraman, A., \& Colby, C. L. (2001). Techno-ready marketing: How and why your customers adopt technology. New York: Free Press.

Schepers, J., \& Wetzels, M. (2007). A meta-analysis of the technology acceptance model: Investigating subjective norm and moderation effects. Information \& Management, 44, 90-103. doi:10.1016/j.im.2006.10.007

Tsikriktsis, N. (2004). A technology readiness-based taxonomy of costumers: A replication and extension. Journal of Service Research 7, 42-52. doi:10.1177/1094670504266132

Venkatesh, V. (2000). Determinants of perceived ease of use: Integrating control, intrinsic motivation, and emotion into the technology acceptance model. Information Systems Research, 11, 342-365. doi:10.1287/isre.11.4.342.11872

Yang, H.-D., \& Yoo, Y. (2004). It's all about attitude: Revisiting the technology acceptance model. Decision Support Systems, 38, 19-31. doi:10.1016/S01679236(03)00062-9

Yi, M. Y., \& Hwang, Y. (2003). Predicting the use of web-based information systems: Self-efficacy, enjoyment, learning goal orientation, and the technology acceptance model. International Journal of Human-Computer Studies, 59, 431449. doi:10.1016/S1071-5819(03)00114-9 